\title{
AUMENTO DA VIOLÊNCIA LEVA A RETROCESSO NAS PRIORIDADES ORÇAMENTÁRIAS
}

Coluna publicada em 26.6.2018: <https://www.conjur.com.br/2018-jun-26/contas-vistaaumento-violencia-leva-retrocesso-prioridades-orcamentarias $>$

\author{
"Se os governadores não construírem escolas, \\ em 20 anos faltará dinheiro para construir presídios."
}

(Darcy Ribeiro, 1982)

Há quatro anos, escrevi sobre o tema da segurança pública e iniciei dizendo: "Assunto que sempre está na ordem do dia, a questão da violência e, por consequência, da segurança pública tem sido objeto de maior destaque nas últimas semanas, em que se tem observado um - no mínimo aparente - aumento da criminalidade". 1

Vários fatos relevantes ocorridos nas últimas semanas justificam retomar o assunto. O curioso - e lamentável - é ver que a forma de iniciar esta coluna pode ser exatamente a mesma de quatro anos atrás. Ou seja: aparentemente, nada mudou.

O caso do assassinato da vereadora carioca Marielle Franco, que repercutiu no mundo todo; o assassinato da menina Vitória Gabrielly, em Araçariguama, interior de São Paulo, causando indignação e revolta no país inteiro; o garoto Marcos Vinícius, há poucos dias vítima fatal de uma bala perdida durante operação policial na comunidade da Maré, nos já corriqueiros tiroteios urbanos no Rio de Janeiro; e tantos outros que ocupam o noticiário quase diariamente.

Um grau de violência que ultrapassa os limites do tolerável (se é que há algum limite que possa ser aceito...), cada vez mais difícil de justificar, especial-

1 Financiamento da segurança pública precisa de atenção, publicada em 6 de maio de 2014, nesta edição, p. 65-68. 
mente em se tratando de uma necessidade pública que sempre esteve entre as prioridades da sociedade brasileira, e mesmo assim não se consegue uma solução para o problema.

O direito à segurança pública é inerente ao Estado Democrático de Direito, estando previsto na Constituição como sendo "um dever do Estado, direito e responsabilidade de todos" para a "preservação da ordem pública e da incolumidade das pessoas e do patrimônio" (Constituição, art. 144, caput), o que lhe confere a característica de um "direito humano, pelos valores que protege e resguarda para uma qualidade de vida comunitária tranquila e pacífica", compreendendo uma ampla gama de direitos, sendo verdadeiro meio de garantia dos direitos fundamentais de todo cidadão, como a vida, liberdade, propriedade e tantos outros. ${ }^{2}$

Como todo direito que tem sua dimensão prestacional, no direito à segurança pública o aspecto financeiro é fundamental para que seja viabilizado. A Medida Provisória 841, de 11 de junho de 2018, reorganizou o mais relevante instrumento financeiro para as políticas públicas no setor, o Fundo Nacional de Segurança Pública, criado em 2001 (Lei 10.201), dispondo sobre as receitas e destinação de seus recursos, trazendo medidas importantes, como o aporte de recursos das loterias federais para compor a arrecadação do fundo. Porém, causará prejuízo de quase $\mathrm{R} \$$ 1 bilhão ao Fies (Fundo de Financiamento Estudantil). Causará também cancelamento de transferências à Cruz Vermelha, às Apaes e às Santas Casas. ${ }^{3} \mathrm{E}$ até recursos destinados à construção de presídios. Ou seja, a conhecida frase do antropólogo Darcy Ribeiro não só parece atual como se transformou em uma profecia que se cumpriu quase à perfeição. Afinal, já se passaram muito mais de 20 anos - quase 40, para ser mais preciso -, e o que se constata é que estão tirando recursos destinados à educação para aplicar na punição.

Dinheiro não nasce em árvores, e a priorização da segurança pública tornou necessária uma "escolha trágica" nas prioridades orçamentárias. E essa medida provisória permitiu materializar com clareza a opção anunciada por Darcy Ribeiro.

Tudo isso decorre da já exaustivamente denunciada falta de planejamento e da adoção da técnica de gestão "administração-bombeiro", que vive para apagar incêndios e agir de improviso, técnica essa nunca defendida por qualquer estudioso, mas amplamente utilizada por todas as esferas de governo.

2 Valter SANTIN. Controle judicial da segurança pública. 2. ed. São Paulo: Verbatim, 2013. p. $47-48$.

3 Temer prevê tirar R \$ 1 bi do Fies para financiar Segurança Pública. Folha de S.Paulo, 21 de junho de 2018, p. B1. 
O imprescindível Plano Nacional de Segurança Pública se perde nos meandros da burocracia do Congresso Nacional para só aparecer quando a violência volta a chamar a atenção, para em seguida voltar a descansar nas prateleiras.

Veja-se que o problema da segurança pública é antigo e recorrente, tanto que a coluna escrita quatro anos atrás já alertava para os mesmos fatos hoje observados.

E o avanço da criminalidade, que não é novidade, apenas se torna mais agudo em função de fatos que vez por outra chamam a atenção da sociedade, levou recentemente à criação do Ministério Extraordinário da Segurança Pública, ${ }^{4}$ dividindo funções antes exercidas pelo Ministério da Justiça. Uma medida evidentemente improvisada, pois não se cria um ministério "da noite para o dia", sem estudos de viabilidade e conveniência, muito menos por medida provisória, até porque a urgência e relevância das questôes de segurança pública são tão antigas que não podem surpreender ninguém.

Com isso, surge um ministério que, embora possa ser até desejável sob o ponto de vista administrativo, começa a funcionar no improviso, sem que esteja organizado adequadamente, sob todos os pontos de vista. Seus recursos humanos, materiais e orçamentários estão alocados em órgãos anteriormente ligados ao Ministério da Justiça, nem sequer há previsão no orçamento, indicando que não havia intenção de criá-lo nem no ano anterior quando a lei foi elaborada. Menos ainda no plano plurianual, nos quais devem estar previstos os programas de duração continuada, como muitos que afetam a segurança pública, não obstante os problemas sejam conhecidos há décadas. E agora, evidentemente, passa a funcionar com ajustes sendo feitos "com o carro em movimento" e em "alta velocidade", já que as medidas são muitas, intensas e necessárias. Mais uma técnica de gestão desaconselhada por qualquer especialista no tema, mas visivelmente a mais utilizada pela administração pública. Nem site próprio o ministério tem, prejudicando inclusive a transparência de suas ações. Assim fica difícil dar certo.

Soma-se a isso a já igualmente improvisada intervenção federal no Rio de Janeiro, que, feita emergencialmente e às pressas, tem dificuldades de produzir resultados efetivos, especialmente em se tratando de questão complexa como esta. ${ }^{5}$

Vê-se que a luta, que era para ser desigual em favor do Estado, que tem todos os meios a seu dispor para enfrentar o problema, vem encontrando dificuldades

\footnotetext{
Medida Provisória 821, de 26 de fevereiro de 2018.

Ver Colapso financeiro leva ao caos social è ì intervenção federal na segurança do Rio de Janeiro, nesta edição, p. 47-52.
} 
para combater o crime - este, sim, cada vez mais bem organizado e "eficiente". Não sujeito às "amarras" do setor público, os criminosos se organizam e agem com muito mais rapidez e facilidade, avançam cada vez mais, e parecem estar ganhando o jogo. Um jogo desleal, pois um dos lados não precisa obedecer ao árbitro, seja ele do campo, principal, assistente ou de vídeo. Esperemos que até o final da Copa não sejam eles a levantar a taça!

Não se pode esquecer que as medidas na área da segurança pública envolvem cooperação federativa ${ }^{6}$ - vide a recente intervenção federal no estado do Rio de Janeiro, com a participação do Exército e da Força Nacional de Segurança, ${ }^{7}$ o que torna ainda mais necessário o planejamento, sem o que é muito difícil fazer com que os entes federados possam agir com eficiência para resolver os graves problemas do setor.

Curioso notar que não faltam estudos para identificar os problemas do setor, elaborados pelo próprio governo, e até mesmo as possíveis soluções. Recente publicação do Ipea em parceria com o Fórum Brasileiro de Segurança Pública, o Atlas da Violência $2018,{ }^{8}$ já na sua $12^{\text {a }}$ edição, registra números assustadores, como o elevado número de homicídios, que no Brasil é 30 vezes superior ao de toda a Europa, e um dos mais elevados na América Latina. ${ }^{9}$ Nele destaca-se a necessidade de melhoria na gestão, com a implementação de um sistema de governança capaz de articular todos os entes federados e criar condições para a coordenação entre os Poderes e as polícias, e com isso ter uma arquitetura institucional que possa planejar e executar as políticas públicas do setor. ${ }^{10}$

Mas somente o conjunto de fatos que vem assustando a população e que tem chamado a atenção nos últimos meses agilizou a tramitação do Susp (Sistema Único de Segurança Pública), já há tempos circulando nos escaninhos do Congresso Nacional, para cuja necessidade de aprovação já havia feito referência na coluna publicada há quatro anos, e se materializou na Lei 13.675, de 11 de junho de 2018, criando a Política Nacional de Segurança Pública e Defesa Social (PNSPDS) e instituindo o Susp, além de determinar à União que institua o Plano Nacional de Segurança Pública e Defesa Social. Agora é ver se será cumprido - uma outra batalha a ser vencida.

6 Nesse aspecto, veja-se a Lei 11.473 , de 10 de maio de 2007, que dispõe sobre a cooperação federativa no âmbito da segurança pública.

7 Por oportuno, criada também "na base do improviso", por meio de decreto presidencial (Decreto 5.289, de 2004), sendo um programa de cooperação federativa, e não um órgão constitucionalmente previsto como integrante do sistema de segurança pública, tal como previsto no artigo 144 da Constituição.

8 CERQUEIRA, Daniel (coord.). Atlas da Violência 2018. Brasília: IPEA-FBSP, 2018.

9 O Atlas da Violência. O Estado de S.Paulo, 22 de junho de 2018.

10 CERQUEIRA, Atlas da Violência 2018, p. 89. 
O fato é que os recursos aplicados na segurança pública são muitos. O orçamento federal do Ministério da Justiça, que até o início do ano abrangia os programas hoje sob comando do Ministério Extraordinário da Segurança Pública, tem dotação que supera os $\mathrm{R} \$ 15$ bilhões. Se acrescentarmos o Ministério da Defesa, somam-se mais R 100 bilhōes. ${ }^{11}$ Considerando que a maior parte dos serviços de segurança pública fica sob responsabilidade dos estados, sem contar as atribuições dos municípios, esses valores aumentam exponencialmente. No estado de São Paulo, a Secretaria da Segurança Pública gerencia mais de R $\$ 21$ bilhôes. ${ }^{12}$ E esses recursos não são os únicos, pois muitas ações voltadas à segurança pública podem estar relacionadas com outros órgãos.

Em suma: é muito dinheiro, não pode ser desperdiçado nem mal aplicado. Estamos em uma verdadeira guerra, não se admitem erros. Com tantos recursos, é possível ter uma situação muito melhor do que a que se está vivenciando. Não é mais possível continuar "apagando incêndios", o que devemos deixar para o Corpo de Bombeiros, não para os administradores públicos.

Este 26 de junho é o Dia Internacional contra o Abuso e Tráfico Ilícito de Drogas, uma boa data para refletir sobre essa que é uma das maiores, se não a maior, fonte de violência e fomentadora do crime organizado.

E, sem prejuízo das medidas emergenciais que precisam ser tomadas durante uma guerra, já passou da hora de pensar nas medidas de longo prazo, que vão levar à solução definitiva da questão. O editorial do $O$ Estado de S.Paulo do último dia 22 foi preciso: "O problema da violência somente será enfrentado quando o Brasil contar com uma rede de ensino básico de qualidade. A educação é decisiva para diminuir a exclusão social e a violência". ${ }^{13}$ Para isso, é preciso manter as prioridades orçamentárias no rumo certo, como destacou Élida Pinto neste mesmo espaço no último dia 19: "Diante do conflito da escassez orçamentária e financeira, educação básica pública, universal, equitativa e de qualidade deve vir primeiro". ${ }^{14}$

Se assim não for, daqui a 20 anos a frase de Darcy Ribeiro continuará sendo atual.

11 Orçamento federal de 2018 - Lei 13.587, de 2018.

12 Orçamento de São Paulo 2018 - Lei estadual 16.646, de 2018.

13 O Estado de S.Paulo, O Atlas da Violência, 22 de junho de 2018.

14 Élida Graziane Pinto, Quão menos farinha, maior há de ser a prioridade da educação básica, publicada em 19 de junho de 2018. 
